\title{
Heart CD36 Expression Is Increased in Murine Models of Diabetes and in Mice Fed a High Fat Diet
}

\author{
Dale E. Greenwalt, ${ }^{\star}$ Stephen H. Scheck, ${ }^{\star}$ and Tonya Rhinehart-Jones * \\ *Department of Biochemistry, Holland Laboratory, American Red Cross, Rockville, Maryland 20855; and ${ }^{\ddagger}$ Biology Department, \\ Loyola Marymount University, Los Angeles, California 90045
}

\begin{abstract}
High levels of CD36 expression are found in triglyceride storing and secreting cells such as differentiated adipocytes and mammary secretory epithelial cells and in some capillary endothelial cells. We have found high levels of CD36 in the capillary endothelium of murine adipose tissue and in cardiac and skeletal muscles. Muscle cells themselves were CD36 negative. No CD36 was found in brain endothelium. Cardiac and skeletal muscle tissues are highly oxidative and catabolize long-chain fatty acids as a source of energy while brain tissue does not use long-chain fatty acids for energy production. Since capillary endothelial cell CD36 expression appeared to correlate with parenchymal cell fatty acid utilization and since $\mathrm{CD} 36$ has been identified recently as a longchain fatty acid-binding protein, we examined heart tissue CD36 expression in murine models of insulin-dependent (nonobese diabetic, NOD) and non-insulin-dependent diabetes mellitus $\left(K K A^{Y}\right)$. Diabetic NOD and KKA ${ }^{Y}$ mice had serum triglyceride levels 2.6- and 4.2-fold higher, respectively, than normal mice and exhibited 7- and 3.5-fold higher levels of heart microsomal CD36, respectively, than control mice. Mice fed a $40 \%$ fat diet expressed heart tissue CD36 at a level 3.5-fold higher than those fed a 9\% fat diet. These data suggest that endothelial cell CD36 expression is related to parenchymal cell lipid metabolism. (J. Clin. Invest. 1995. 96:1382-1388.) Key words: dietary fat • endothelium • diabetes mellitus $\cdot$ membrane proteins $\cdot$ triglyceride
\end{abstract}

\section{Introduction}

The integral membrane protein CD36 has a number of putative ligands including thrombospondin (1), oxidized LDL (2), long-chain fatty acids (3), and collagen (4). However, several of these assignments are controversial and it is unlikely that CD36 interacts with all of these disparate molecules in a physio-

A preliminary report of this work was presented at the national meeting of The American Society for Cell Biology in San Francisco on 12 December 1994. Portions of this work were published in abstract form (1994. Mol. Biol. Cell. 5:245a).

Address correspondence to Dale E. Greenwalt, Biochemistry Department, Holland Laboratory, American Red Cross, 15601 Crabbs Branch Way, Rockville, MD 20855. Phone: 301-738-0546; FAX: 301-7380794; E-mail: greenwaltd@usa.red-cross.org.

Received for publication 10 March 1995 and accepted in revised form 31 May 1995.

J. Clin. Invest.

(C) The American Society for Clinical Investigation, Inc.

0021-9738/95/09/1382/07 \$2.00

Volume 96, September 1995, 1382-1388 logically relevant manner. The tissue distribution of a protein can frequently provide valuable information regarding its possible function. CD36 is unique in that it is highly expressed by adipocytes and mammary secretary epithelial cells, both of which are actively involved in fatty acid uptake and synthesis and storage and/or secretion of triacylglycerol. No other type of epithelial cell is know to express CD36. CD36 is also expressed in capillary endothelial cells of some but not all tissues. CD36 is not expressed by the endothelium of large arterial vessels or the capillary endothelium of the brain (5-7). High levels of CD36 expression are found on capillary endothelial cells of adipose and lactating mammary tissues and in cardiac and skeletal muscle $(6,8)$. Since cardiac and skeletal muscles, but not brain tissue, are highly oxidative and capable of oxidizing large amounts of long-chain fatty acids (9), it is tempting to hypothesize that capillary endothelial cell CD36 expression may be related to parenchymal cell lipid metabolism.

A series of recent studies by Abumrad and colleagues have identified CD36 as the major adipocyte cell surface protein labeled by derivatized long-chain fatty acids (10) and a protein that is strongly induced during the adipocyte differentiation process (3). Although free fatty acids and other hydrophobic molecules can spontaneously insert into and move through the phospholipid bilayer (11), strong evidence exists for proteinmediated fatty acid transport. Fatty acid uptake by cells is saturable $(12,13)$ and substrate specific (i.e., transport of long- but not short-chain fatty acid [14-16]). Protease treatment of cells $(15,17)$ and membrane-impermeable reagents such as $4,4^{\prime}$ diisothiocyanostilbene-2,2'-disulfonate, which covalently modifies free amino groups $(15,16)$, inhibit fatty acid uptake as do antisera to specific membrane proteins in adipocytes and the intestinal epithelial cell membrane $(17,18)$. An excellent candidate for a long-chain fatty acid transporter was cloned recently by Schaffer and Lodish (19). The protein, designated FATP, has a molecular mass of $63 \mathrm{kD}$ and increased oleic acid uptake in FATP-transfected 3T3 cells by three- to fourfold. FATP has six putative membrane-spanning regions and, as such, is more likely to have a transport function than CD36, which has only one or two membrane-spanning regions. CD36 is known to be involved in signal transduction in platelets and monocytes $(20,21)$ and has been shown to be associated with cytosolic protein tyrosine kinases in platelets and endothelial cells $(22$, 23). CD36 may function to transduce a signal directly as a result of specific ligand (long-chain fatty acid) binding. Alternatively, long-chain fatty acids may interact with CD36 to affect the conformation or quaternary structure of the protein in a manner that would indirectly affect the ligand-binding characteristics and signal transduction mechanism of CD36 or the functions of adjacent proteins.

Increased levels of triacylglycerol in the blood would lead to increased lipoprotein lipase-mediated free fatty acid concentrations at the luminal surface of cardiac muscle capillary endo- 
thelial cells. We have hypothesized that if CD36 is directly or indirectly involved in the metabolism of plasma fatty acids in parenchymal cells then increased levels of plasma triglycerides would result in increased expression of endothelial cell CD36. This hypothesis has been examined in murine models of diabetes and mice fed a high fat diet.

\section{Methods}

Materials. Aprotinin, $\epsilon$-aminocaproic acid, phenylmethylsulfonyl fluoride, rabbit IgG, and biotinylated goat anti-rabbit IgG were obtained from Sigma Chemicals (St. Louis, MO). SDS-PAGE molecular weight standards were purchased from Bio-Rad Laboratories (Hercules, CA). Enzymatic assay kits for glucose (No. 857429) and triglyceride (No. 450032) were purchased from Boehringer Mannheim Diagnostics (Indianapolis, IN). Enhanced chemiluminescence (ECL) ${ }^{1}$ reagents, $\left[\alpha{ }^{32} \mathrm{P}\right]-$ dCTP, and the random-primer cDNA labeling kit were from Amersham Corp. (Arlington Heights, IL). Avidin-biotin-peroxidase immunohistochemical staining reagents $(A B C)$ were purchased from Vector Laboratories (Burlingame, CA). A cDNA probe for murine $\beta$-actin was obtained from the American Type Culture Collection (Rockville, MD). Purified von Willebrand factor was provided by L. Hoyer (Holland Laboratory, Rockville, MD).

Animals. Male $\mathrm{KKA}^{\mathrm{Y}}$ mice 5 mo of age were obtained from The Upjohn Company (Kalamazoo, MI). Female nonobese diabetic (NOD) mice ( 5 mo of age) and female C57BL/6 mice ( 6 mo of age) were obtained from Taconic Farms (Germantown, NY). Female Swiss Webster mice 2.5 mo of age were obtained from Simonsen Laboratories (Gilroy, CA).

Normal and high fat diets. Swiss Webster mice were housed in groups of six and maintained on a 12:12 day/night cycle at $\sim 24^{\circ} \mathrm{C}$. Half of the mice were placed on a control diet (No. 5001 laboratory rodent diet; PMI Feeds Division of Purina, Inc., St. Louis, MO) from which $9 \%$ of total daily calories came from fat. The remaining mice were fed a high fat diet from which the animals obtained $40 \%$ of their daily caloric intake from lard. All mice had access to food and water ad libitum and were maintained on the diets for $5 \mathrm{wk}$

Immunohistochemistry. Mouse tissues were fixed in methanol/chloroform/acetic acid (60:30:10) and embedded in paraffin. Sections (7 $\mu \mathrm{m})$ were deparaffinized in xylene and ethanol and incubated with either monospecific rabbit antibody No. 1207 to human platelet CD36 (24) or rabbit IgG at final immunoglobulin concentrations of $10 \mu \mathrm{g} / \mathrm{ml}$. CD36 was visualized after subsequent incubations with biotinylated goat antirabbit IgG, avidin-biotin-peroxidase complex, and diaminobenzidine. Immunostained sections were counterstained with hematoxylin.

Immunoblots and densitometry. Fresh hearts were trimmed of any attached nonmuscle tissue and the bottom (ventricular) two-thirds of each organ was minced with scissors at $4^{\circ} \mathrm{C}$ in Tris-buffered saline containing $1 \%$ aprotinin, in $2 \mathrm{mM} \epsilon$-aminocaproic acid and $0.5 \mathrm{mM}$ phenylmethylsulfonyl fluoride and homogenized at $4^{\circ} \mathrm{C}$ with two $10-$ s bursts of a tissue homogenizer (model 2000; OMNI International, Waterbury, CT). The homogenate was centrifuged at $1,000 \mathrm{~g}$ for $5 \mathrm{~min}$ to remove large unhomogenized fragments, and the supernatant was centrifuged again at $100,000 \mathrm{~g}$ for $1 \mathrm{~h}$ to obtain microsomal and supernatant fractions. Human platelets were prepared as described previously (24). Mouse platelets were obtained from blood collected by cardiac puncture into heparin $(10 \mathrm{U} / \mathrm{ml})$ and made $4 \mathrm{mM}$ in citrate and $2 \mathrm{mM}$ in EDTA. Erythrocytes and the buffy coat were pelleted, and the plateletrich plasma $\left(1.3 \times 10^{8}\right.$ platelets $\left./ \mathrm{ml}\right)$ was centrifuged for $10 \mathrm{~min}$ at $2,000 \mathrm{~g}$.

Microsomes or supernatant $(50 \mu \mathrm{g} / \mathrm{lane})$ and platelets $\left(10^{7} / \mathrm{lane}\right)$ were diluted in Laemmli SDS-PAGE lysis buffer and their proteins were

1. Abbreviations used in this paper: ECL, enhanced chemiluminescence; FABP, fatty acid-binding protein; NOD, nonobese diabetic.
Table I. Tissue-specific Expression of Murine Capillary Endothelial Cell CD36

\begin{tabular}{lc}
\hline Tissue type & Degree of staining* \\
\hline Lung & - \\
Liver & - \\
Kidney & - \\
Pancreas & - \\
Cerebrum & - \\
Muscle & \\
Cardiac & +++ \\
Skeletal & +++ \\
Smooth & + \\
Adipose & +++ \\
Spleen & + \\
\hline
\end{tabular}

* The degree of staining was determined by visual examination of immunohistochemically stained tissue sections and is based on a relative scale of - (no CD36-positive capillaries) to +++ (numerous intensely stained CD36-positive capillaries). Five mice in total were examined.

separated on $10 \%$ acrylamide reducing SDS-PAGE gels. The proteins were transferred to nitrocellulose membrane, stained with Ponceau $S$, and destained and blocked with $1 \%$ gelatin, $2 \%$ goat serum, $0.1 \%$ bovine serum albumin, and $0.05 \%$ Tween 20 in Tris-buffered saline, $\mathrm{pH} 7.5$. Immunoblots were developed with either monospecific rabbit antibody (No. 1207) to human platelet CD36, rabbit antiserum (No. R40-2) to human von Willebrand factor, rabbit antiserum against human platelet glycoprotein IIbIIIa (25), or rabbit nonimmune IgG. CD36 was visualized after incubation with biotinylated goat anti-rabbit IgG and ECL reagents according to the manufacturer's instructions (Amersham Corp.). The ECL films obtained from multiple exposures were scanned with a Lynx Imaging System Video Densitometer (Applied Imaging Corp., Santa Clara, CA). Separate parallel SDS-PAGE gels containing identical sample volumes were processed for each immunoblot. These gels were stained with Coomassie and dried, and bands at $\sim 45$ and $200 \mathrm{kD}$ were quantified by densitometry as controls for sample loading. Slight variations in the protein loading were used to normalize CD36 values derived from densitometric analysis of immunoblot ECL films. In some experiments, the Ponceau $\mathbf{S}$-stained nitrocellulose membrane was scanned into a computer data base and analyzed with the NIH Image 1.54 program (National Institutes of Health, Bethesda, MD).

Northern blots. Total RNA from mouse heart tissue or adipose tissue (as a positive control) was isolated as described by Chomczynski and Sacchi (26). Total RNA ( $20 \mu \mathrm{g} / \mathrm{lane})$ was separated on a $1 \%$ agarose/ formaldehyde gel and transferred to a nylon membrane. The membrane was then hybridized with adipocyte-specific fatty acid-binding protein (FABP) cDNA random-labeled with $\left[{ }^{32} \mathrm{P}\right] \mathrm{dCTP}$ in $50 \%$ formamide for $20 \mathrm{~h}$ at $42^{\circ} \mathrm{C}$. A similarly labeled $\beta$-actin cDNA was used as a control for sample loading. After three washes in $1 \times \mathrm{SSC}$ at $37^{\circ} \mathrm{C}$, the membrane was exposed to $\mathrm{x}$-ray film.

Analytical techniques. Microsomal protein concentrations were determined by the BCA assay (27) in the presence of $1 \%$ SDS. Blood was collected by cardiac puncture, and serum glucose and triglyceride levels were determined by enzymatic assays with reagents obtained from Boehringer Mannheim Diagnostics. Statistical significance was determined with the Student's $t$ test.

\section{Results}

Immunohistochemical analysis of capillary endothelial cell CD36 expression. The occurrence of CD36 in capillary endothelial cells is tissue specific (Table I). Of 10 different murine 

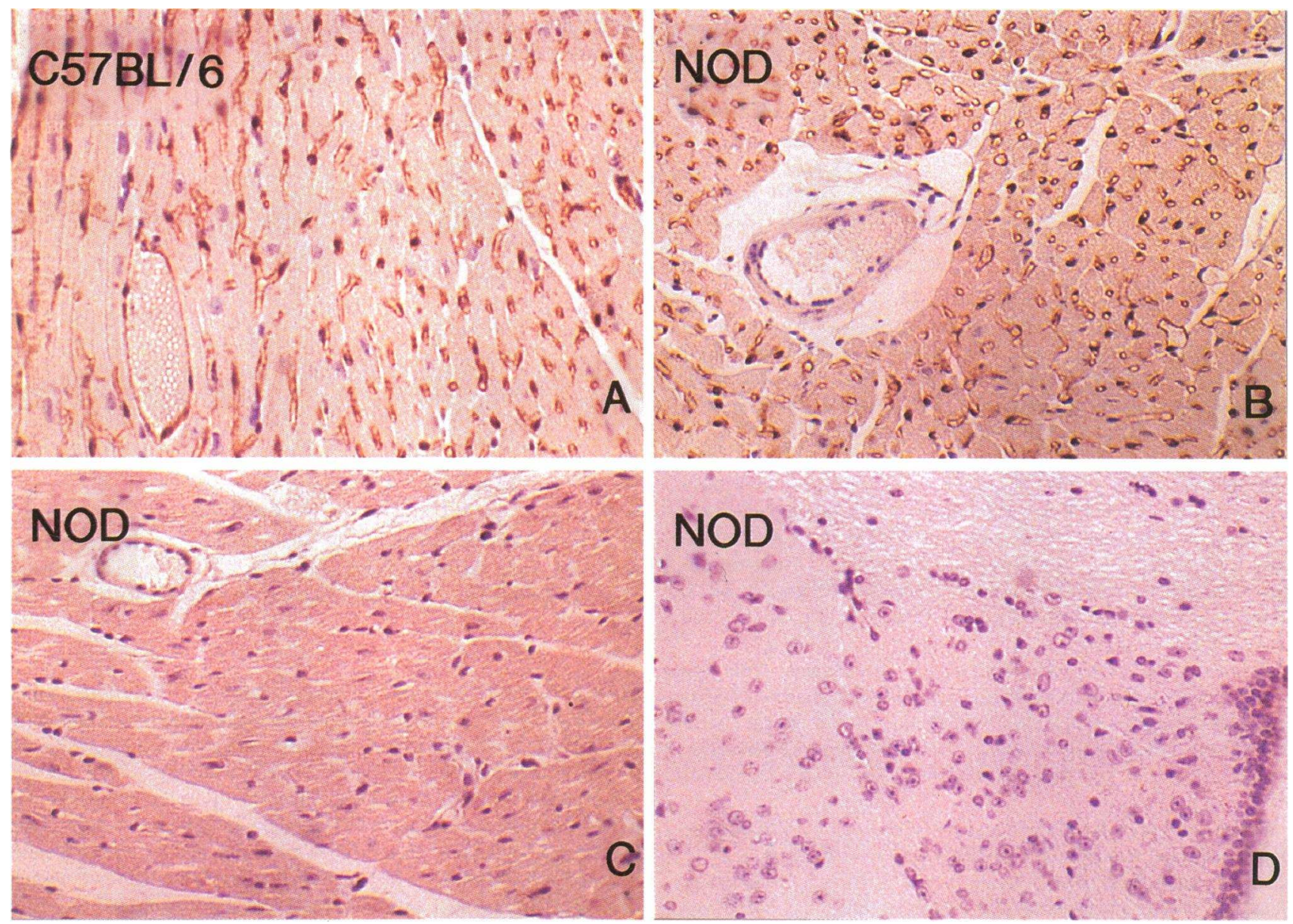

Figure 1. Immunohistochemical localization of CD36 in murine tissues. Fresh tissues from C57BL/6 $(A)$ or NOD $(B-D)$ mice were fixed in methacarn, and paraffin sections of the heart $(A-C)$ or brain $(D)$ were stained with monospecific polyclonal antibodies to $\mathrm{CD} 36(A, B$, and $D)$ or $10 \mu \mathrm{g} / \mathrm{ml}$ rabbit nonimmune $\operatorname{IgG}(C) . \times 150$.

tissues examined, CD36 was most strongly expressed in the capillaries of adipose tissue and cardiac and skeletal muscles. Differentiated mammary tissue was not examined. While individual smooth muscle capillaries expressed CD36, the total number of capillary vessels was low compared with skeletal and cardiac muscle. The capillary endothelial cells of several tissues, including the brain, were completely CD36 negative (Fig. 1).

CD36 expression in heart tissue was restricted to the capillary endothelium in both normal and diabetic mice (Fig. 1). Muscle cells did not express plasmalemmal CD36, and examination of the tissue sections counterstained with hematoxylin and eosin did not reveal the presence of adipose tissue. Blood vessels in the tissue sections did contain erythrocytes and presumably CD36-positive platelets and monocytes. However, the contribution of blood cell CD36 to total heart tissue CD36 was negligible ( see below). The actual number of microvessels in the cardiac muscles of the different experimental groups of mice used in this study did not vary significantly.

Immunoblot analyses of CD36 expression in NOD mice. The NOD mouse is an animal model of insulin-dependent diabetes mellitus (28). Female NOD mice are particularly prone to the development of diabetes with $\sim 70 \%$ hyperglycemic by $30 \mathrm{wk}$ of age (29). In the present study, three of six female 6-moold NOD mice were hyperglycemic. Diabetic NOD mice had average blood glucose levels two- to fivefold higher than either control C57BL/6 or nondiabetic NOD mice (Fig. 2). Immunoblot analysis of cardiac muscle microsomes with antibody to CD36 revealed a marked increase in CD36 levels in fasting diabetic NOD mice (Fig. 2). Plasma triglyceride levels were also greatly increased in diabetic NOD mice and correlated

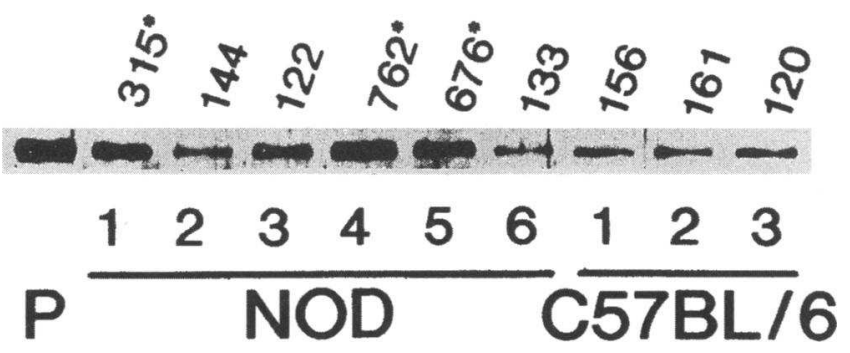

Figure 2. Increased CD36 expression in heart muscle microsomes of fasting diabetic NOD mice. Heart muscle microsomes ( $50 \mu \mathrm{g}$ ) from six different NOD mice and three C57BL/6 mice were analyzed for CD36 by an immunoblot with monospecific antibodies to CD36. Human platelets $\left(10^{7}\right)$ were used as a positive control $(P)$. The values above each lane of microsomal CD36 denote the blood glucose level of each animal. Animals with blood glucose levels marked with an asterisk were designated as diabetic. 


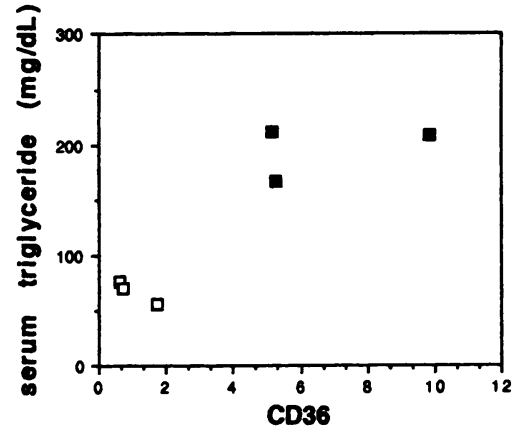
analysis of an immunoblot of heart microsomes with monospecific antiserum to CD36. The average of the three C57BL/6 CD36 values is given an arbitrary value of 1.0

with a sevenfold increase in CD36 levels relative to C57BL/6 controls (Fig. 3). Immunohistochemical analysis of diabetic NOD mouse heart and brain tissues revealed CD36 expression patterns identical to those of normal mice (Fig. 1 and Table I).

Control experiments designed to ascertain the contribution of CD36-positive cell types other than capillary endothelial cells to $\mathrm{CD} 36$ levels were also performed. Heart microsomes from C57BL/6 control and diabetic NOD mice were also analyzed for mouse platelet glycoprotein IIbIIIa as a measure of platelet membrane contamination of the microsomes. Murine platelets $\left(10^{7} /\right.$ lane $)$ were used as a positive control. Immunoblot analysis of $50 \mu \mathrm{g}$ of heart microsomal protein, an amount sufficient to provide a strong signal for $\mathrm{CD} 36$, indicated that platelet CD36 contributed a maximum of $3 \%$ of the microsomal CD36 content (data not shown).

Although adipose tissue was not observed either on the cardiac tissue used for preparation of microsomes or in histological preparations of the heart tissues, contamination of the microsomes with adipocyte membranes was of concern because of the high level of CD36 expression in differentiated adipocytes. Since antibody against adipose FABP which did not also react with heart muscle cell FABP was not available, a cDNA probe specific for adipose FABP was used to detect adiposespecific FABP messenger RNA in control and diabetic NOD mouse heart tissue. Low amounts of adipocyte-specific FABP messenger RNA were detectable in both control and diabetic mouse heart tissue. Calculations based on the signal obtained with the adipose tissue control indicated that adipose tissue in the hearts used in these experiments contributed $<5 \%$ of the CD36 levels reported in this study (data not shown).

Immunoblot analysis of CD36 expression in $K K A^{Y}$ mice. The $\mathrm{KKA}^{\mathrm{Y}}$ mouse is an animal model of non-insulin-dependent diabetes mellitus characterized by extremely high levels of serum triglyceride $(30,31)$. In the present study, $\mathrm{KKA}^{\mathrm{Y}}$ mice had blood glucose and plasma triglyceride levels of $589 \pm 67$ and $328 \pm 44 \mathrm{mg} / \mathrm{dl}$, respectively. These values were 3.4-fold (glucose) and 4.0-fold (triglyceride) greater than those found for C57BL/b control mice (Figs. 2 and 3 ). $\mathrm{KKA}^{\mathrm{Y}}$ heart microsomal CD36 levels were 3.5-fold greater than in C57BL/6 control mice (Fig. 4). The increase in cardiac muscle microsomal CD36 in the $\mathrm{KKA}^{\mathrm{Y}}$ mice was less than the 5-10-fold increase observed in the diabetic NOD mice despite nearly identical blood glucose levels and considerably higher serum triglyceride levels ( $328 \pm 44$ vs. $199 \pm 24 \mathrm{mg} / \mathrm{dl}$ ).

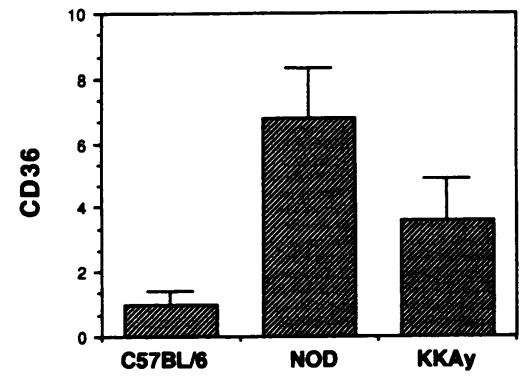

Figure 4. Relative levels of CD36 expression in the heart muscle microsomes of normal and diabetic mice. CD36 was quantitated by densitometric analysis of immunoblots of heart microsomes with monospecific antiserum to $\mathrm{CD} 36$. C57BL/6 CD36 values were arbitrarily assigned a value of 1.0. Diabetic NOD and $\mathrm{KKA}^{\mathrm{Y}}$ values are significant at the $P<0.01$ and $P=0.05$ levels, respectively. For each strain of mouse, $n=3$.

Immunoblot analysis of CD36 expression in mice fed a high fat diet. To extend our analysis to yet another model of hypertriglyceridemia, female Swiss-Webster mice were placed on diets of normal (9\% fat as a percentage of total caloric intake) or high (40\%) fat. After $5 \mathrm{wk}$, fasting blood glucose levels of the mice on normal and high fat chow were not significantly different. Serum triglyceride levels were $57 \pm 2.1$ and $74 \pm 9.8 \mathrm{mg} / \mathrm{dl}$ for the mice fed normal and high fat chow, respectively $(P=0.010)$. In an initial experiment with six mice on each diet, immunoblot analysis of heart microsomal CD36 revealed a 3.8-fold increase in the mice fed high fat chow (Fig. $5 A$, high fat\#l). The experiment was repeated with another 12 mice and, again, a more than threefold increase in heart muscle CD36 was observed (Fig. 5 A, high fat\#2). Immunohistochemical analysis of heart tissue from the mice fed high fat chow did not reveal any CD36-positive cell type other than the capillary endothelium (data not shown).

To determine that the observed increase in CD36 was specific for CD36 and not characteristic of endothelial cell antigens in general, levels of the endothelial cell marker von Willebrand

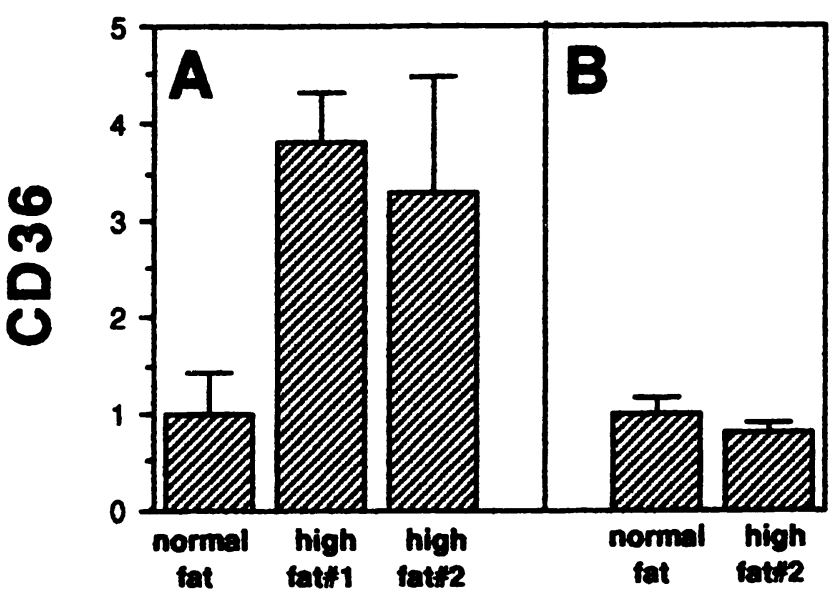

Figure 5. Heart muscle microsomal CD36 expression in mice fed a high fat diet. CD36 levels of mice fed a normal fat (9\% of total caloric intake) are arbitrarily set at 1.0. Two separate trials were done, each consisting of six mice on a normal fat diet and six mice on a high fat $(40 \%)$ diet. ( $A$ ) Differences in CD36 levels in trials 1 and 2 relative to normal values were significant at the $P<0.001$ and $P<0.01$ levels, respectively. $(B)$ Levels of the endothelial cell marker protein von Willebrand factor were not significantly different in hearts from mice fed normal and high fat diets. 
factor were determined. Immunoblot analysis of supernatant fractions of heart tissue homogenates from the 12 mice in trial 2 with antiserum to von Willebrand factor did not reveal a significant difference in the levels of this endothelial cell marker protein (Fig. 5 B).

\section{Discussion}

This study was based on the observation that several tissues that have highly CD36-positive capillary endothelia all use large amounts of fatty acids for either triglyceride synthesis and storage (adipose), triglyceride synthesis and secretion (mammary epithelium), or oxidation and energy production (cardiac and skeletal muscles). We hypothesized that in the microvasculature of tissues involved in fatty acid transport and metabolism high circulating triglyceride levels would induce increased expression of fatty acid transporters and/or related proteins. Three different models of murine hypertriglyceridemia were examined. NOD mice, a model of insulin-dependent diabetes mellitus (29), and $\mathrm{KKA}^{\mathrm{Y}}$ mice, a model of insulin-independent diabetes mellitus (31), had serum triglyceride levels 2.7 - and 4.4-fold higher than control mice. In a third model, mice fed a diet enriched in fat for 5 wk had serum triglyceride levels $30 \%$ higher than those of mice on a normal diet. In all three models, heart muscle capillary endothelial CD36 was found to increase 3-10-fold. The observation that CD36 levels were not strictly proportional to serum triglyceride values may suggest that factors unique to a particular model may affect the expression of CD36.

The CD36 expression observed in this study appears to be due to capillary endothelial cell expression only. Northern blot analysis of normal and diabetic NOD heart tissue RNA failed to detect significant levels of adipose FABP mRNA, a marker for the presence of adipose tissue. In addition, immunoblot assays for platelet glycoprotein IIbIIIa did not suggest a significant contribution of CD36 by platelets. Microscopic examination of the heart tissues did not reveal CD36-positive cells other than the capillary endothelium, in agreement with previous observations (6). However, muscle cells are present in vast excess to endothelial cells, and a small increase in muscle cell CD36, not detectable by immunohistochemical techniques, could exist. Van Nieuwenhoven and colleagues recently reported low levels of CD36 mRNA in isolated rat cardiomyocytes (32). Neither detection of CD36 protein nor immunohistochemical analysis was attempted. This particular study also reported that two rat heart-derived endothelial cell lines were CD36 negative. Interpretation of these data must take into consideration the possibility that the endothelial cell lines were derived from CD36negative large vessels or ceased CD36 expression in culture. The possibility of CD36 expression by muscle cells is intriguing but as yet uncorroborated.

The data reported in this study establish a correlation between heart muscle capillary endothelial cell CD36 expression and blood triglyceride levels. Earlier studies have shown that purified CD36 will specifically bind long-chain fatty acids (Abumrad, N., manuscript in preparation) and adipocyte cell membrane CD36 can be specifically labeled by sulfo- $N$-succinimidyl oleate (10), a long-chain fatty acid that effectively inhibits adipocyte fatty acid transport (14). In addition, Abumrad and colleagues (3) demonstrated that increases in CD36 mRNA in differentiating adipose cells parallel the development of oleate uptake activity. CD36 has also been identified as a receptor for oxidized but not normal or acetylated LDL (2). Of interest, a recent study by Nicholson and colleagues has shown that free oleic acid can effectively inhibit the binding of oxidized LDL to CD36-transfected 3T3 cells (33).

CD36 is a member of a gene family that includes hamster SR-BI (CLA-1A in the human [34, 35]), a lysosomal protein termed LIMP II (36), a Caenorhabditus elegans cDNA, and two Drosophila sequences $(37,38)$. CD36 itself is expressed in adipose tissue, differentiated mammary epithelium, and a variety of blood cells including megakaryocytes, macrophages, and erythroblasts (39). CD36 is also expressed on endothelial cells but in a tissue-specific manner. Large arterial vessel endothelial cells are CD36 negative as are capillary endothelial cells of the brain and certain other tissues $(5,6)$. In all species examined, CD36 is most strongly expressed in the capillary endothelial cells of adipose tissue, differentiated mammary epithelial tissue, and cardiac and skeletal muscles $(6,7$, and this study).

A protein with $32 \%$ amino acid sequence identity to human CD36 termed SR-B1 (scavenger receptor type B1) has been expressed recently and found to bind oxidized and acetylated LDL and maleylated serum albumin (34). SR-B1, but not CD36, was also reported to bind normal LDL. CD36 itself was found to bind acetylated LDL and maleylated serum albumin in contrast to results reported by Endemann et al. (2). SR-B1 is expressed at very high levels in adipose tissue, and like CD36, is induced upon adipocyte differentiation (34). Another CD36related protein, LIMP II, has been shown to cycle between the cell surface and the lysosomal compartment of cultured hepatocytes (40). The function of LIMP II is unknown.

The ability of cells transfected with CD36 cDNA to bind oxidized LDL has been established in several different studies $(2,33,34)$. However, the amount of oxidized LDL bound via CD36 is low relative to the scavenger receptor, as is CD36mediated internalization and degradation. CD36-transfected Chinese hamster ovary cells in fact do not internalize oxidized LDL (Lipsky, R., manuscript submitted for publication). The ability of free fatty acid to prevent binding of oxidized LDL to CD36 (33) suggests that oxidized LDL-CD36 interaction may be a minor function of CD36. It may be pertinent to note two observations that may relate to the physiological role of CD36oxidized LDL interaction. First, mammary secretory epithelial cell CD36 is located only on the apical membrane (6). Milk, the physiological fluid in contact with the secretory cell apical membrane, does not contain LDL. Second, the endothelial cells of large arterial vessels, the primary site of oxidized LDL accumulation, do not express CD36. The major cell type responsible for oxidized LDL uptake in arterial vessels is the macrophage (41). Since macrophages also express CD36, it would be interesting to determine if monocytes and/or macrophages isolated from diabetic mice express increased levels of CD36.

The expression of FABP, a cytosolic FABP unrelated to CD36, has also been shown to increase in the heart muscle of diabetic animals relative to normal controls (42). While FABP is integrally involved in intracellular fatty acid transport, this $15-\mathrm{kD}$ protein has also been shown to regulate cardiomyocyte hypertrophy (43) and mammary epithelial cell differentiation (44). It is of interest to note that FABP and CD36 are both found in the membrane that surrounds the droplets of triglyceride (milk fat globules) in milk (45). Whether or not a functional or physical relationship exists between CD36 and FABP is not known. 
The exact function of $\mathrm{CD} 36$ relative to fatty acid transport and/or metabolism has yet to be determined. While we do not propose that CD36 is itself a transporter, CD36 could serve as a fatty acid sensor and/or could indirectly mediate fatty acid transport through the endothelial cell plasmalemma. While the demonstration that purified CD36 will specifically bind longchain fatty acids (Abumrad, N., manuscript in preparation) may suggest only that CD36 has a hydrophobic pocket, the data from the present study suggest that the role of CD36-fatty acid interaction is of physiological significance in vivo. The original observations of Abumrad and colleagues $(3,10,14)$ and recent descriptions of interactions between CD36 and SR-B1 with various forms of $\operatorname{LDL}(2,33,34)$ all indicate that CD36 does indeed play a role in lipid metabolism. Whether oxidized LDL, free fatty acids, or oxidized fatty acids are all physiologically relevant ligands of CD36 or partially mimic one another is unknown. Experiments that demonstrate specific long-chain fatty acid induction of endothelial cell CD36 expression in vitro and/ or fatty acid influence on CD36-mediated signal transduction would help to define this role.

TNF has been shown recently to induce CD36 expression in normally CD36-negative human umbilical cord endothelial cells (46). Additionally, TNF-activated endothelial cells were shown to mediate greatly enhanced expression of CD36 in adherent monocytes. In another study (47), transfection of normally nonphagocytotic Bowes melanoma and COS-7 cells with CD36 produced cells capable of the phagocytosis of apoptotic neutrophils. TNF is a potent activator of endothelial cells and has been implicated in the pathogenesis of both insulin-dependent and non-insulin-dependent diabetes mellitus (48). It would be interesting to determine if endothelial cells of diabetic tissues have an increased ability to recognize and/or phagocytize apoptotic cells.

\section{Acknowledgments}

We wish to thank Dr. George Melchior of Upjohn Laboratories for the $\mathrm{KKA}^{\mathrm{Y}}$ mice, Narendra Tandon for antiserum No. 1207, and Leon Hoyer for purified von Willebrand factor and rabbit serum to von Willebrand factor. We also acknowledge the assistance of Nada Abumrad with the Northern blot.

This work was supported by National Institutes of Health grant CA56589 (D. E. Greenwalt) and NASA-JOVE NAG8-275 (S. H. Scheck).

\section{References}

1. Asch, A. S., J. Barnwell, R. L. Silverstein, and R. L. Nachman. 1987. Isolation of the thrombospondin membrane receptor. J. Clin. Invest. 79:10541061.

2. Endemann, G., L. W. Stanton, K. S. Madden, C. M. Bryant, R. T. White, and A. A. Protter. 1993. CD36 is a receptor for oxidized low density lipoprotein. J. Biol. Chem. 268:11811-11816.

3. Abumrad, N. A., M. R. El-Maghrabi, E. Z. Amri, E. Lopez, and P. A Grimaldi. 1993. Cloning of a rat adipocyte membrane protein implicated in binding or transport of long-chain fatty acids that is induced during preadipocyte differentiation. J. Biol. Chem. 268:17665-17668.

4. Tandon, N. N., R. H. Lipsky, and W. H. Burgess. 1989. Isolation and characterization of platelet glycoprotein IV (CD36). J. Biol. Chem. 264:75707575.

5. Turner, G. D. H., H. Morrison, M. Jones, T. M. E. Davis, S. Looareesuwan, I. D. Buley, K. C. Gatter, C. I. Newbold, S. Pukritayakamee, B. Nagachinta, et al. 1994. An immunohistochemical study of the pathology of fatal malaria. Evidence for widespread endothelial activation and a potential role for intercellular adhesion molecule-1 in cerebral sequestration. Am. J. Pathol. 145:1057-1069.

6. Greenwalt, D. E., and I. H. Mather. 1985. Characterization of an apically derived epithelial membrane glycoprotein from bovine milk, which is expressed in capillary endothelia in diverse tissues. J. Cell Biol. 100:397-408.

7. Knowles, D. M., B. Tolidjian, C. Marboe, V. D. Agati, M. Grimes, and L. Chass. 1984. Monoclonal anti-human monocyte antibodies OKM1 and OKM5 possess distinctive tissue distributions including differential reactivity with vascular endothelium. J. Immunol. 132:2170-2173.

8. Jochen, A., and J. Hays. 1993. Purification of the major substrate for palmitoylation in rat adipocytes: $\mathrm{N}$-terminal homology with CD36 and evidence for cell surface acylation. J. Lipid Res. 34:1783-1792.

9. Neely, J. R., M. J. Rovetto, and J. F. Oram. 1972. Myocardial utilization of carbohydrate and lipids. Prog. Cardiovasc. Dis. 15:289-329.

10. Harmon, C. M., and N. A. Abumrad. 1993. Binding of sulfosuccinimidyl fatty acids to adipocyte membrane proteins: isolation and amino-terminal sequence of an 88-kD protein implicated in transport of long-chain fatty acids. J. Membr. Biol. 133:43-49.

11. Kamp, F., and J. A. Hamilton. 1993. Movement of fatty acid, fatty acid analogues, and bile acids across phospholipid bilayers. Biochemistry. 32:1107411086.

12. Abumrad, N. A., R. C. Perkins, J. H. Park, and C. R. Park. 1981. Mechanism of long chain fatty acid permeation in the isolated adipocyte. J. Biol. Chem. 256:9183-9191.

13. Abumrad, N. A., S. A. Melki, and C. M. Harmon. 1990. Transport of fatty acid in the isolated rat adipocyte and in differentiating preadipose cells. Biochem. Soc. Trans. 18:1130-1132.

14. Harmon, C. M., P. Luce, A. H. Beth, and N. A. Abumrad. 1991. Labeling of adipocyte membranes by sulfo- $N$-succinimidyl derivatives of long-chain fatty acids: inhibition of fatty acid transport. J. Membr. Biol. 121:261-268.

15. Abumrad, N. A., J. H. Park, and C. R. Park. 1984. Permeation of longchain fatty acid into adipocytes. J. Biol. Chem. 259:8945-8953.

16. Storch, J., C. Lechene, and A. M. Kleinfeld. 1991. Direct determination of free fatty acid transport across the adipocyte plasma membrane using quantitative fluorescence microscopy. J. Biol. Chem. 266:13473-13476.

17. Schwieterman, W., D. Sorrentino, B. J. Potter, J. Rand, C. L. Kiang, D. Stump, and P. D. Berk. 1988. Uptake of oleate by isolated rat adipocytes is mediated by a $40-\mathrm{kDa}$ plasma membrane fatty acid binding protein closely related to that in liver and gut. Proc. Natl. Acad. Sci. USA. 85:359-363.

18. Stremmel, W., G. Lotz, G. Strohmeyer, and P. D. Berk. 1985. Identification, isolation, and partial characterization of a fatty acid binding protein from rat jejunal microvillous membranes. J. Clin. Invest. 75:1068-1076.

19. Schaffer, J. E., and H. F. Lodish. 1994. Expression cloning and characterization of a novel adipocyte long chain fatty acid transport protein. Cell. 79:427436.

20. Schuepp, B. J., H. Pfister, K. J. Clemetson, R. L. Silverstein, and T. W. Jungi. 1991. CD36-mediated signal transduction in human monocytes by antiCD36 antibodies but not by anti-thrombospondin antibodies recognizing cell membrane-bound thrombospondin. Biochem. Biophys. Res. Commun. 175:263270.

21. Trezzini, C., T. W. Jungi, M. O. Spycher, F. E. Maly, and P. Pao. 1990 Human monocyte CD36 and CD16 are signaling molecules. Evidence from studies using antibody-induced chemiluminescence as a tool to probe signal transduction. Immunology. 71:29-37.

22. Huang, M.-M., J. B. Bolen, J. W. Barnwell, S. J. Shattil, and J. S. Brugge. 1991. Membrane glycoprotein IV (CD36) is physically associated with the fyn, lyn and yes protein-tyrosine kinases in human platelets. Proc. Natl. Acad. Sci. USA. 88:7844-7848.

23. Bull, H. A., P. M. Brickell, and P. M. Dowd. 1993. The cytoplasmic protein tyrosine kinase $\mathrm{p} 59^{f y m}$ is physically associated with the surface antigen CD36 in human dermal microvascular endothelial cells. Clin. Res. 41:446A

24. Tandon, N. N., U. Kralisz, and G. A. Jamieson. 1989. Identification of GPIV (CD36) as a primary receptor for platelet-collagen adhesion. J. Biol. Chem. 264:7576-7583.

25. Greenwalt, D. E., K. W. K. Watt, O. Y. So, and N. Jiwani. 1990. PAS IV, an integral membrane protein of mammary epithelial cells, is related to platelet and endothelial cell CD36 (GPIV). Biochemistry. 29:7054-7059.

26. Chomczynski, P., and N. Sacchi. 1987. Single-step method of RNA isolation by acid guanidinium thiocyanate-phenol-chloroform extraction. Anal. Biochem. 162:156-159.

27. Smith, P. K., R. I. Krohn, G. T. Hermanson, A. K. Mallia, F. H. Gartner, M. D. Provenzano, E. K. Fujimoto, N. M. Goeke, B. J. Olson, and D. C. Klenk. 1985. Measurement of protein using bicinchoninic acid. Anal. Biochem. 150:7685.

28. Tochino, Y. 1987. The NOD mouse as a model of type I diabetes. CRC Crit. Rev. Immunol. 8:49-81.

29. Makino, S., K. Kunimoto, Y. Muraoka, Y. Mizushima, K. Katagiri, and Y. Tochino. 1980. Breeding of a non-obese diabetic strain of mice. Exp. Anim. (Tokyo). 29:1-13.

30. Iwatsuka, H., A. Shino, and Z. Suzuoki. 1970. General survey of diabetic features of yellow KK mice. Endocrinol. Jpn. 17:23-35.

31. Fujita, T., Y. Sugiyama, S. Taketomi, T. Sohda, Y. Kawamatsu, H. Iwatsuka, and Z. Suzuoki. 1983. Reduction of insulin resistance in obese and/or 
diabetic animals by 5-[4-(methylcyclohexylmethoxy)benzyl]-thiazolidine-2,4dione (ADD-3878,U-63287, ciglitazone), a new antidiabetic agent. Diabetes. 32:804-810

32. Van Nieuwenhoven, F. A., C. P. H. J. Verstijnen, N. A. Abumrad, P. H. M. Willemsen, G. J. J. M. Van Eys, G. J. van der Vusse, and J. F. C. Glatz 1995. Putative membrane fatty acid translocase and cytoplasmic fatty acid-binding protein are co-expressed in rat heart and skeletal muscles. Biochem. Biophys. Res. Commun. 207:747-752.

33. Nicholson, A. C., S. Frieda, A. Pearce, and R. L. Silverstein. 1995. Oxidized LDL binds to CD36 on human monocyte-derived macrophages and transfected cell lines. Arterioscler. Thromb. Vasc. Biol. 15:269-275.

34. Acton, S. L., P. E. Scherer, H. F. Lodish, and M. Krieger. 1994. Expression cloning of SR-BI, a CD36-related class B scavenger receptor. J. Biol. Chem. 269:21003-21009.

35. Calvo, D., and M. A. Vega. 1993. Identification, primary structure, and distribution of CLA-1, a novel member of the CD36/LIMPII gene family. $J$. Biol. Chem. 268:18929-18935.

36. Vega, M. A., B. Segui-Real, J. A. Garcia, C. Cales, F. Rodriguez, J. Vanderkerckhove, and I. V. Sandoval. 1991. Cloning, sequencing and expression of a cDNA encoding rat LIMP II, a novel 74-kDa lysosomal membrane protein related to the surface adhesion protein CD36. J. Biol. Chem. 266:16818-16824.

37. Waterston, R., C. Martin, M. Craxton, C. Huynh, A. Coulson, L. Hillier, R. Durbin, P. Green, R. Shownkeen, N. Halloran, et al. 1992. A survey of expressed genes in Caenorhabditus elegans. Nat. Genet. 1:114-123.

38. Hart, K., and M. Wilcox. 1993. A Drosophila gene encoding an epithelial membrane protein with homology to CD36/LIMP II. J. Mol. Biol. 234:249-253.

39. Greenwalt, D. E., R. H. Lipsky, C. F. Ockenhouse, H. Ikeda, N. N. Tandon, and G. A. Jamieson. 1992. Membrane glycoprotein CD36: a review of its roles in adherence, signal transduction and transfusion medicine. Blood. 80:1105-1115.
40. Akasaki, K., A. Michihara, M. Fukuzawa, H. Kinoshita, and H. Tsuji. 1994. Cycling of an $85-\mathrm{kDa}$ lysosomal membrane glycoprotein between the cel surface and lysosomes in cultured rat hepatocytes. J. Biochem. 116:670-676.

41. Witztum, J. L., and D. Steinberg. 1991. Role of oxidized low density lipoprotein in atherogenesis. J. Clin. Invest. 88:1785-1792.

42. Glatz, J. F. C., E. van Breda, H. A. Keizer, Y. F. de Jong, J. R. T. Lakey, R. V. Rajotte, A. Thompson, G. J. van der Vusse, and G. D. Lopaschuk. 1994 Rat heart fatty acid-binding protein content is increased in experimental diabetes. Biochem. Biophys. Res. Commun. 199:639-646.

43. Burton, P. B. J., C. E. Hogben, C. L. Joannou, A. G. B. Clark, J. J. Hsuan, N. F. Totty, C. Sorensen, R. W. Evans, and M. J. Tynan. 1994. Heart fatty acid binding protein is a novel regulator of cardiac myocyte hypertrophy. Biochem. Biophys. Res. Commun. 205:1822-1828.

44. Yang, Y., E. Spitzer, N. Kenney, W. Zschiesche, M. Li, A. Kromminga, T. Muller, F. Spener, A. Lezius, J. H. Veerkamp, et al. 1994. Members of the fatty acid binding protein family are differentiation factors for the mammary gland. J. Cell Biol. 127:1097-1109.

45. Brandt, R., M. Pepperle, A. Otto, R. Kraft, F.-D. Boehmer, and R. Grosse. 1988. A 13-kilodalton protein purified from milk fat globule membranes is closely related to a mammary-derived growth inhibitor. Biochemistry. 27:1420-1425.

46. Huh, H. Y., S. K. Lo, L. M. Yesner, and R. L. Silverstein. 1995. CD36 induction on human monocytes upon adhesion to tumor necrosis factor-activated endothelial cells. J. Biol. Chem. 270:6267-6271.

47. Ren, Y., R. L. Silverstein, J. Allen, and J. Savill. 1995. CD36 gene transfer confers capacity for phagocytosis of cells undergoing apoptosis. J. Exp. Med. 181:1857-1862.

48. Argiles, J. M., J. Lopez-Soriano, and F. J. Lopez-Soriano. 1994. Cytokines and diabetes: the final step? Involvement of TNF-alpha in both type I and II diabetes mellitus. Horm. Metab. Res. 26:447-449. 